\title{
Zorunlu Bireysel Emeklilik Sistemine Geçiş ve Yapılacak Kesintilerin Muhasebeleştirilmesi
}

\author{
Sema AKPINAR* \\ Merve GÜNEŞ DEMIRCI **
}

\section{ÖZET}

Türkiye'de 2001 yllında uygulanmaya başlanan Bireysel Emeklilik Sistemi 02.01.2017 tarihinde Resmi Gazete'de yaytnlanan yönetmelik ile kamu ve özel sektörde çalışan 45 yaş altındaki tüm çalışanlara zorunlu hale getirilmiştir. Kurumdaki personel sayısına göre Bireysel Emeklilik Sistemine zorunlu giriş tarihleri değişiklik göstermektedir. Yapılan bu çalışmada sisteme zorunlu giriş sonucunda sağlık sektörü çalışanlarının ücretlerinden yapılacak muhtemel kesinti tutarları ve kesintinin hangi hesapta muhasebeleştirileceği ile ilgili örnekler verilmiştir. Bu yolla uygulayıcılara destek olmak amaçlanmaktadır.

Anahtar Kelimeler: Bireysel Emeklilik Sistemi, Muhasebe, Ücret Bordrosu.

JEL Sinıflandırması: M41, I13.

\section{Transition to Compulsory İndividual Pension System and Accounting for Discontinuities}

\section{ABSTRACT}

The Individual Pension System, which started to be implemented in Turkey in 2001, has become compulsory for all employees under the age of 45 working in the public and private sectors with the regulation published in the Official Gazette on 02nd January 2017. According to the number of personnel at the institution, compulsory entry dates to Individual Pension System have been changed. In this study, As a result of forced entry into the system, examples are given concerning possible deductions from the wages of health sector employees and how these will be accounted for. It is aimed to support practitioners in this way.

Keywords: Individual Pension System, Accounting, Wages Sheet.

Jel Classification: M41, I13.

\footnotetext{
*Yrd. Doç. Dr. Sema Akpınar, Sakarya Üniversitesi İşletme Fakültesi, semaulku@sakarya.edu.tr

** Merve Güneş Demirci, Sakarya Üniversitesi Sosyal Bilimler Enstitüsü, merve.demirci5@ogr.sakarya.edu.tr
} 


\section{GİRiş}

Geçmiş dönemlerle kıyaslandığında günümüzde dünya nüfusunun giderek yaşlanması ve bunun yanında tıp alanında meydana gelen yenilikler sayesinde ortalama ömrün uzamış olması çalışanlar ve emekliler arasındaki mevcut dengeyi bozarak sosyal güvenlik sistemi üzerinde önemli bir yük oluşturmuştur. Söz konusu sosyal güvenlik sisteminin sürdürülebilirliğini korumak amacıyla emeklilik yaşı, emeklilik aylığına hak kazanma süresi gibi faktörlerin yeniden gözden geçirildiği, ayrıca dağıtımda yaşanan mali problemlerin üstesinden gelmek için alternatif sistemler geliştirildiği görülmektedir. Söz konusu sistemlerden biri olan Bireysel Emeklilik Sistemi 1981 yılında Şili'de ortaya çıkmıştır. 1992 yılında Peru ve 1997 yılında Meksika'nın uygulamaya aldığı sistem ve yıllar içinde pek çok ülkeye örnek olmuştur. Çalışanların gönüllü katılımıyla işleyen ve çalışanlara esas itibariyle ek nitelikte emeklilik yardımı sağlayan fon esasına dayalı ikinci bir rejim olarak bilinen bireysel emeklilik sistemi 2001 yılında Türkiye'de de uygulamaya koyulmuştur ve yapılan son kanuni düzenleme ile birlikte etkinliğini arttırması beklenmektedir. Bu çalışmada bireysel emeklilik sistemine zorunlu geçiş düzenlemesi kapsamında sağlı sektörü çalışanlarının ücretlerinden yapılacak muhtemel kesinti tutarlar1 ve kesintinin hangi hesapta muhasebeleştirilebileceği ile ilgili örnekler tasarlanmıştır.

\section{BİREYSEL EMEKLILIIK SISTEMINE GENEL BAKIŞ}

Devlet tarafından desteklenen sosyal güvenlik sistemlerine yardımcı olmak için özel sigorta şirketleri tarafından bireysel emeklilik sistemi adı verilen sistem oluşturulmuştur. Bireysel Emeklilik Sistemi (BES), 2001 yılında 4632 sayılı kanunla Türkiye'de yürürlüğe girmiştir. Sistemin amacı devletin sosyal güvenlik sistemini tamamlayıcı olarak, şahısların emeklilik dönemine yönelik tasarruflarını arttırmak ve emekli olduklarında ek bir kazanç sağlayarak refah düzeylerini arttırmak, ekonomiye uzun vadeli kaynak oluşturarak katk1 sağlamaktır. Sistem ilk kurulduğunda gönüllü katılım esasını benimsemiştir (BES,2001, md.1). Sisteme dâhil olan bireyler, giriş tarihinden itibaren en az on yıl sistemde kalmak durumundadır ve söz konusu kişiler elli altı yaşını tamamladıktan sonra emekli olma hakkını kazanmaktadırlar. Yine bu kişiler emekli olduktan sonra ödemeyi isterlerse tamamen, isterlerse aylık şeklinde almayı talep edebilirler (BES,2001, md.6). 2012 y1lından itibaren BES sistemine dâhil olan ve 56 yaşına kadar sistemden çıkmayanlara \%25 devlet katkısı verilmeye başlanmıştır (BES,2012, ek md.1). Bireysel Emeklilik Sisteminin Türkiye'de tarihsel gelişimi Tablo 1'de gösterilmiştir.

Tablo 1. Yıllara Göre Bireysel Emeklilik Sisteminin Gelişimi

\begin{tabular}{|l|r|r|r|r|r|}
\hline & $\begin{array}{c}\text { Katılımcı } \\
\text { Sayısı }\end{array}$ & $\begin{array}{c}\text { Devlet Katkısı } \\
\text { Fon Tutarı }\end{array}$ & Katkı Payı Tutarı & $\begin{array}{c}\text { Sözleşme ve } \\
\text { Sertifika } \\
\text { Sayısı }\end{array}$ & $\begin{array}{c}\text { Yatırıma } \\
\text { Yönlendirilen } \\
\text { Toplam Tutar }\end{array}$ \\
\hline $\mathbf{3 1 . 1 2 . 2 0 0 3}$ & 15.245 & & $5.866 .764 \mathrm{TL}$ & 16.812 & $5.692 .556 \mathrm{TL}$ \\
\hline $\mathbf{3 1 . 1 2 . 2 0 0 4}$ & 314.257 & & $288.325 .706 \mathrm{TL}$ & 334.577 & $276.287 .104 \mathrm{TL}$ \\
\hline $\mathbf{3 1 . 1 2 . 2 0 0 5}$ & 672.696 & & $1.117 .233 .826 \mathrm{TL}$ & 714.146 & $1.078 .630 .423 \mathrm{TL}$ \\
\hline $\mathbf{3 1 . 1 2 . 2 0 0 6}$ & 1.073 .650 & & $2.592 .508 .977 \mathrm{TL}$ & 1.141 .428 & $2.512 .373 .823 \mathrm{TL}$ \\
\hline $\mathbf{3 1 . 1 2 . 2 0 0 7}$ & 1.457 .704 & & $3.917 .061 .211 \mathrm{TL}$ & 1.576 .273 & $3.786 .517 .089 \mathrm{TL}$ \\
\hline $\mathbf{3 1 . 1 2 . 2 0 0 8}$ & 1.745 .354 & & $5.467 .695 .761 \mathrm{TL}$ & 1.933 .266 & $5.284 .206 .740 \mathrm{TL}$ \\
\hline $\mathbf{3 1 . 1 2 . 2 0 0 9}$ & 1.987 .940 & & $7.102 .007 .561 \mathrm{TL}$ & 2.203 .886 & $6.869 .992 .691 \mathrm{TL}$ \\
\hline $\mathbf{3 1 . 1 2 . 2 0 1 0}$ & 2.281 .478 & & $9.515 .230 .234 \mathrm{TL}$ & 2.534 .840 & $9.221 .131 .447 \mathrm{TL}$ \\
\hline
\end{tabular}




\begin{tabular}{|l|l|l|l|l|l|}
\hline & & & & & \\
\hline 31.12.2011 & 2.641 .843 & & $12.393 .688 .644 \mathrm{TL}$ & 2.939 .878 & $12.028 .485 .722 \mathrm{TL}$ \\
\hline $\mathbf{3 1 . 1 2 . 2 0 1 2}$ & 3.128 .130 & & $16.177 .757 .755 \mathrm{TL}$ & 3.496 .377 & $15.741 .037 .013 \mathrm{TL}$ \\
\hline $\mathbf{3 1 . 1 2 . 2 0 1 3}$ & 4.153 .055 & $1.151 .765 .932 \mathrm{TL}$ & $21.921 .860 .114 \mathrm{TL}$ & 4.687 .675 & $21.455 .900 .238 \mathrm{TL}$ \\
\hline $\mathbf{3 1 . 1 2 . 2 0 1 4}$ & 5.092 .871 & $3.019 .076 .239 \mathrm{TL}$ & $28.346 .503 .495 \mathrm{TL}$ & 5.807 .319 & $27.842 .765 .911 \mathrm{TL}$ \\
& & & & & \\
\hline $\mathbf{3 1 . 1 2 . 2 0 1 5}$ & 6.038 .432 & $5.020 .000 .071 \mathrm{TL}$ & $37.119 .095 .559 \mathrm{TL}$ & 7.040 .375 & $36.549 .379 .287 \mathrm{TL}$ \\
\hline $\mathbf{3 1 . 1 2 . 2 0 1 6}$ & 6.625 .759 & $7.438 .167 .182 \mathrm{TL}$ & $44.351 .386 .577 \mathrm{TL}$ & 7.789 .185 & $43.720 .675 .782 \mathrm{TL}$ \\
\hline
\end{tabular}

Kaynak: egm.org.tr adresindeki veriler doğrultusunda hazırlanmıştır.

2003-2016 yılları arasında Bireysel Emeklilik Sistemindeki gelişimi gösteren Tablo 1 incelendiğinde on üç yıllık süre içerisinde gönüllü katılım esasına göre sisteme 6.625.759 kişi katılmıştır. 2012 yılından itibaren (devletin bireysel emeklilik sistemine katkısının başlaması) sisteme katılım hızlı bir şekilde artmıştır. 2003-2012 yılı arasında on yıllık süreçte sisteme 3.128.130 kişi katılmışken, devletin sistemi desteklemesinin ardından 4 yılda katılımcı sayısı iki kattan daha fazla artmış ve 6.625.759 kişiye ulaşmıştır. Katkı payı tutarları incelendiğinde 2012 y1lında 16.177.757.755 TL bulunmakta iken, 2016 sonu itibariyle katk1 payı tutarı 44.351.386.577 TL'ye yükselmiştir. 4 yıllık süre içerisinde devlet sisteme 7.438.167.182 TL kaynak aktarımı yapmıştır.

01.01.2017 tarihinde Hazine Müsteşarlığının 18.11.2016 tarih ve 32665 sayılı "Çalışanların İşverenleri Aracılığıyla Otomatik Olarak Emeklilik Planına Dâhil Edilmesine İlişkin Usul ve Esaslar Hakkında Yönetmelik" ile BES kamu ve özel sektörde çalışan 45 yaş altında tüm çalışanlara zorunlu hale gelmiştir (Hazine Müsteşarlığı, 2017). Kamu idarelerinde en erken 01/04/2017 en geç 01.01.2018 tarihinde sisteme dâhil olma zorunluluğu vardır. Özel sektörde ise;

- $\quad 1000$ personel ve üzeri çalışanı olan şirketler 01.01.2017 tarihinde çalışanlarını sisteme dahil ederken,

- $\quad 249$ ile 1000 arası çalışanı bulunan firmalar 1 Nisan 2017 tarihinden itibaren,

- $\quad 100$ ila 249 kişi arasında çalışanı bulunan firmalar 1 Eylül 2017 tarihinden itibaren, tarihinden itibaren,

50 ila 100 çalışanı olan firmalar ile tüm yerel yönetimler 1 Ocak 2018

- $\quad 10$ ile 50 arasında çalışanı olan firmalar için 1 Temmuz 2018‘den itibaren,

- $\quad$ çalışan sayısı 5 kişiden az olan şirketler ise çalışanlarını 01.01.2019 tarihinde sisteme dahil edeceklerdir.

Katkı payı hesaplanırken prime esas kazancın veya emeklilik keseneğine esas aylı̆̆ın yüzde üçü oranında hesaplanacaktır. Hesaplamada virgülden sonraki küsurat kısmı dikkate alınmayacaktır. İşverenler BES için yaptıkları kesintiyi ilgili özel emeklilik şirketine aktarmak durumundadırlar (Hazine Müsteşarlığı, 2017, md.6 - 7). Bireysel Emeklilik Sistemine zorunlu katılımda işverenlerin anlaşma yapabilecekleri şirketler Tablo 2'de gösterilmiştir. 
Tablo 2. BES Yapmaya Yetkili Hayat Sigortası Şirketleri

\begin{tabular}{|l|l|}
\hline 1 & Aegon Emeklillik ve Hayat AŞ \\
\hline 2 & Allianz Hayat ve Emeklilik AŞ \\
\hline 3 & Allianz Yaşam ve Emeklilik AŞ \\
\hline 4 & Anadolu Hayat ve Emeklilik AŞ \\
\hline 5 & Asya Emeklilik ve Hayat AŞ \\
\hline 6 & AvivaSA Emeklilik ve Hayat AŞ \\
\hline 7 & Axa Hayat ve Emeklilik AŞ \\
\hline 8 & BNP Paribas Cardif Emeklilik AŞ \\
\hline 9 & Cigna Finans Emeklilik ve Hayat AŞ \\
\hline 10 & Fiba Emeklilik ve Hayat AŞ \\
\hline 11 & Garanti Emeklilik ve Hayat AŞ \\
\hline 12 & Groupama Emeklilik AŞ \\
\hline 13 & Halk Hayat ve Emeklilik AŞ \\
\hline 14 & NN Hayat ve Emeklilik AŞ \\
\hline 15 & Katılım Emeklilik ve Hayat AŞ \\
\hline 16 & Metlife Emeklilik ve Hayat AŞ \\
\hline 17 & Vakıf Emeklilik AŞ \\
\hline 18 & Ziraat Hayat ve Emeklilik AŞ \\
\hline
\end{tabular}

Bireysel emeklilik sistemine aktarılacak fonlar personelin hak ettiği brüt ücret üzerinden kesinti yoluyla ilgili şirketlere aktarılacaktır. Yani fon ödemelerini işverenler işçileri adına ödeyecek, BES ve diğer kesintiler sonrası net ücreti personellerine ödeyeceklerdir. Bireysel Emeklilik Sistemi kesintisinin yanı sıra çalışan personelin maaşından SGK ve vergi kesintileri de yapılmaktadır.

Kişinin ücretinden bireysel emeklilik fonu dışında yapılacak kesintiler ve hangi hesapların kullanılacağı Tablo 3'de gösterilmiştir.

Tablo 3. Personelin Ücretinden Yapılacak Kesintiler

\begin{tabular}{|l|l|c|}
\hline \multicolumn{2}{|c|}{} \\
\cline { 1 - 2 } Sosyal Güvenlik Kurumu İşçi Payı & Brüt Ücret x \%14 & $\begin{array}{c}\text { 361 Ödenecek Sosyal Güvenlik } \\
\text { Kesintileri }\end{array}$ \\
\hline Sosyal Güvenlik Kurumu İşsizlik Fonu & Brüt Ücret x \%1 & \multirow{2}{*}{360 Ödenecek Vergi ve Fonlar } \\
\cline { 1 - 2 } Gelir Vergisi & $\begin{array}{l}\text { (Brüt Ücret-SGK } \\
\text { Kesintileri)x \%15 }\end{array}$ & \\
\cline { 1 - 2 } Damga Vergisi & Brüt Ücret x \%0,759 & \\
\hline
\end{tabular}

Kaynak: (Arsoy, 2014:179)

Personelden yapılan sigorta kesintileri 361 Ödenecek Sosyal Güvenlik Kesintileri hesabında, vergi kesintileri ise 360 Ödenecek Vergi ve Fonlar hesabında takip edilecektir. İşveren personelin brüt ücreti üzerine ek olarak SGK'ye ödeme yapmaktadır. Yapılacak kesintiler ve kullanılacak hesaplar Tablo 4'te gösterilmiştir.

Tablo 4. Brüt Ücretin Üzerinden İşveren Tarafından Yapılacak Ödemeler

\begin{tabular}{|l|c|c|}
\hline Sigorta Kolu & İşveren Pay1 (\%) & Hesap Kodu \\
\hline Malullük, Yaşlılık ve Ölüm & 11 & \multirow{3}{*}{ 361 Ödenecek Sosyal Güvenlik } \\
Kısa Vadeli Sigorta Kolları & 2 & Kesintileri \\
\hline Genel Sağlık Sigortası & 7,5 & \\
\hline İşsizlik Sigortası & 2 & \\
\hline Toplam & 22,5 & \\
\hline
\end{tabular}

Kaynak: www.sgk.gov.tr sitesinden hazırlanmıştır. 
Tablo 4'te işverenin brüt ücret üzerinden SGK'ye ödenmesi gereken paylar gösterilmiştir. Yapılacak kesintiler 361 Ödenecek Sosyal Güvenlik Kesintileri hesabında izlenecektir. 26720 Numara ve 04.12.2007 tarihli Resmi Gazete'de yayınlanan 265 Seri No'lu Gelir Vergisi Genel Tebliği ile Asgari Geçim İndirimi (AGI) uygulanmaya başlanmıştır. Tebliğ AGI'nin hesaplanması ile ilgili “Asgarî geçim indirimi; ücretin elde edildiği takvim yılı başında geçerli olan ve sanayi kesiminde çalışan 16 yaşından büyük işçiler için uygulanan asgarî ücretin yıllık brüt tutarının; mükellefin kendisi için \% 50'si, çalışmayan ve herhangi bir geliri olmayan eşi için \% 10'u, çocukların her biri için ayrı ayrı olmak üzere; ilk iki çocuk için \% 7,5 diğer çocuklar için \% 5'idir " ifadesine yer vermiştir. Hesaplanan AGİ tutarı 136 Diğer Çeşitli Alacaklar hesabında takip edilecektir. AGİ her yıl Ocak ve Temmuz ayında olmak üzere iki kez güncellenmektedir. 2017 yılının ilk altı aylık dönemi için hesaplanan AGİ Tablo 5 'te gösterilmiştir.

Tablo 5. 2017 Yı1ı Asgari Geçim İndirimi

\begin{tabular}{|c|c|}
\hline Bekâr Çalışan & 133,31 TL \\
\hline Evli ve Eşi Çalışan & 133,31 TL \\
\hline Evli, Eşi Çalışan ve 1 Çocuk Sahibi & 153,30 TL \\
\hline Evli, Eşi Çalışan ve 2 Çocuk Sahibi & 173,30 TL \\
\hline Evli, Eşi Çalışan ve 3 Çocuk Sahibi & 199,96 TL \\
\hline Evli, Eşi Çalışan ve 4 Çocuk Sahibi & 213,30 TL \\
\hline Evli ve Eşi Çalışmayan & 159,97 TL \\
\hline Evli, Eşi Çalış̧mayan ve 1 Çocuk Sahibi & 179,97 TL \\
\hline Evli, Eşi Çalşmayan ve 2 Çocuk Sahibi & 196,96 TL \\
\hline Evli, Eşi Çalışmayan ve 3 Çocuk Sahibi & 226,63 TL \\
\hline Evli, Eşi Çalışmayan ve 4 Çocuk Sahibi & 226,63 TL \\
\hline
\end{tabular}

Yukarıda açıklanan kesintilere ek olarak 2017 yılı itibariyle işverenler çalışanların brüt ücretinin \%3’ünü Bireysel Emeklilik Sistemine aktarması gerekmektedir. Ancak aktarım SGK dışında özel bir emeklilik şirketine yapılacağından 361 Ödenecek Sosyal Güvenlik Kesintileri hesabının kullanılması doğru olmayacaktır. Bu yüzden yapılacak kesinti ile ilgili çalışmada iki hesap önerilmektedir. Bunlardan birincisi "336 Diğer Çeşitli Borçlar" hesabı diğeri ise “369 Ödenecek Diğer Yükümlülükler” hesabıdır. Uygulama kısmında detaylı şekilde açıklanan kesintiler ve kullanılacak hesaplar iki örnek üzerinden incelenecektir.

\section{LITERATÜR TARAMASI}

$\mathrm{Bu}$ bölümde bireysel emeklilik sistemine ilişkin ulusal literatürde yer alan bazı çalışmalara yer verilmiştir:

Apak ve Taşçıyan'ın (2010, Türkiye'deki bireysel emeklilik sisteminin gelişimin inceleyen çalışmasında bireysel emeklilik sistemine ait ikincil veriler analiz edilmiştir. Yıllar itibariyle sistemin katılımcı sayısı ve fon bakımından büyüdüğü, katılımcıların genellikle 2544 yaş aralığında olduğu ve çoğunlukla aylık ödeme periyodunu tercih ettikleri bulgularına ulaşılmıştır.

İşseveroğlu ve Hatunoğlu (2012), yaptıkları çalışma ile makroekonomik faktörlere etkisi kapsamında ülkedeki bireysel emeklilik sisteminin güçlü ve zayıf yönlerinin belirlenmesi firsat ve tehditlerin de ortaya koymayı amaçlamıştır. Sistemin şeffaf oluşu, vergi 
teşviki ve devlet katkısının bulunması güçlü yanları arasında gösterilirken, ülkede sigorta kültürünün eksik olması, bireysel emeklilik fonlarının hedeflenen şekilde değerlendirilmemesi, asgari getiri garantisinin bulunmaması gibi unsurlar zayıf yanları olarak ifade edilmiştir. Tasarruf yeteneği düşük olan gelir gruplarına nazaran yüksek gelir gruplarının vergi avantajı sağlamak adına sisteme girmesi bir tehdit olarak algılanırken, çalışanlar için oluşturulacak kıdem fonunun BES içinde değerlendirilmesi ile fon büyüklüğünü arttırabilecek bir firsat olarak sunulmuştur.

Uyar (2012), bireysel emeklilik sisteminin makroekonomik etkilerini inceleyerek bireysel emeklilik sistemi verileri ile temel ekonomik göstergeler arasında anlamlı bir ilişki olup olmadığını araştıran çalışmasında elde ettiği bulgulara göre bireysel emeklilik sistemi göstergelerinden sertifika sayısı ile makroekonomik göstergelerden mevduat faizi arasında anlamlı bir ilişki tespit etmiştir. Buna göre ilgili dönemden bir önceki dönemin mevduat faizi ilgili dönemin sertifika sayısı üzerinde etkilidir. Ayrıca söz konusu dönemdeki sertifika sayısı da bir sonraki dönemin mevduat faizini etkilemektedir.

Yaman ve Emir (2012), Türkiye'de bireysel emeklilik sisteminin işleyişi, muhasebe yapısı, denetimi, vergi teşvikleri ve sistemdeki ceza hükümlerini inceledikleri çalışmada sistemin sağladığı vergi avantajlarının katılımcılar tarafından yeterince bilinmediği ve bu sebeple vergi teşviklerinden faydalanamadıklarına vurgu yapmıştır. Çözüm önerisi olarak tanıtım eksikliğinin giderilmesi ve bu yolla sistemin gelişimin sağlanması fikirleri sunulmuştur.

Kızılgeçit (2014), Türkiye'de bireysel emeklilik alanında hizmet sunan sigorta şirketlerinin 2010-2012 yılları arasındaki performansını ölçmek amacıyla yaptığı çalışmasında performans ölçümünde etkinlik düzeyini esas almıştır ve yöntem olarak veri zarflama analizini kullanmıştır. Söz konusu yıllar arasında etkin olan sigorta şirketleri ile etkin olmayan şirketlerin referans almaları gereken şirketler belirlenmiştir.

Sezgin ve Yıldırım'ın (2015), Türkiye' deki bireysel emeklilik sisteminin etkinliği üzerinde durdukları çalışmada, sistemle ilgili bilgi eksikliğinin önemli bir sorun olduğu, ülkede uzun vadeli birikim anlayışının olmamasının sistemin etkinliğini olumsuz yönde etkilediği, devlet katkısının ise sistemi son dönemlerde cazip hale getirdiği ifade edilmiştir.

\section{4. ÖRNEK UYGULAMALAR}

Bu kısımda Bireysel Emeklilik Sistemi ile ilgili yukarıda yapılan açıklamalar iki örnek uygulama ile gösterilmiştir. Yapılan örnek uygulamalarda önce brüt ücret üzerinden yapılacak kesintiler hesaplanmış ardından ilgili muhasebe kayıtları gösterilmiştir.

\section{Örnek 1}

Brüt ücreti 6.000 TL olan bekâr bir doktorun Ocak ayı ücretinden yapılacak kesinti oranları ve tutarları aşağıdaki gibidir:

SGK İşçi Payı: \%14

SGK İşsizlik Sigortası İşçi Payı: \%1

B.E.S. :\%3

Gelir Vergisi: \%15
SGK İşveren Payı: \%20,5

SGK İşsizlik Sigortası İşveren Payı: \%2

Damga Vergisi:\%0,759

A.G.I. : 133,31 TL 
Doktorun ücretinden ilk olarak Sosyal Güvenlik Kesintileri yapılacaktır. \%14 SGK İşçi Payı, \%1 SGK İşsizlik Sigortası kesintisi yapılacaktır. Yapılan kesintiler 361 Ödenecek Sosyal Güvenlik Kesintileri hesabında izlenecektir. SGK kesintilerinin ardından Gelir ve Damga Vergisi kesintileri yapılacaktır. Gelir Vergisi matrahı brüt ücretten SGK kesintileri düşüldükten sonra kalan tutarın \%15,20,27,35 (Personelin bulunduğu vergi dilimine göre) olarak hesaplanacaktır. Damga vergisi ise $\% 0,759$ olarak brüt ücret üzerinden hesaplanacaktır. Yapılan vergi kesintileri 360 Ödenecek Vergi ve Fonlar hesabında takip edilecektir. Bu kesintiler yapıldıktan sonra kalan tutar personelin net ücreti olarak tahakkuk ettirilmektedir. Ancak yapılan yeni düzenleme ile yapılan kesintilere ek olarak Bireysel Emeklilik Sistemi içinde brüt ücret üzerinden $\% 3$ kesinti yapılacaktır. Yapılacak bu kesinti işveren tarafından anlaşmalı özel sigorta şirketine devredilecektir. Yapılacak kesinti için Tek Düzen Hesap Planı'nda özel bir hesap bulunmamaktadır. BES kesintisini önceki bölümde önerildiği gibi “336 Diğer Çeşitli Borçlar” veya “369 Ödenecek Diğer Yükümlülükler” hesabında izlenmesi uygun olacaktır. İşçinin ücretinden yapılan kesinti oranları ve tutarlar aşağıdaki tabloda gösterilmektedir.

Tablo 6. Çalışanın Ücretinden Yapılacak Kesinti Tutarları

\begin{tabular}{|c|c|c|}
\hline SGK İşçi Payı & 6.000 TL $x \% 14$ & $840 \mathrm{TL}$ \\
\hline SGK İşsizlik Sigortası İşçi Pay1 & 6.000 TL $x \% 1$ & $60 \mathrm{TL}$ \\
\hline Gelir Vergisi & {$[6.000 \mathrm{TL}-(840 \mathrm{TL}+60 \mathrm{TL})] \times \mathrm{\%} 15$} & $765 \mathrm{TL}$ \\
\hline Damga Vergisi & $6.000 \mathrm{TL} \times \% 0,759$ & $45,54 \mathrm{TL}$ \\
\hline B.E.S. & 6.000 TL $x \% 3$ & $180 \mathrm{TL}$ \\
\hline
\end{tabular}

Personelin işverene maliyeti ise personelin brüt ücreti + işveren SGK payları olarak hesaplanacaktır. SGK işveren payı $\% 20,5$, SGK işsizlik sigortası işveren payı ise $\% 2$ olarak belirtilmiştir. Yapılacak kesinti "361 Ödenecek Sosyal Güvenlik Kesintileri” hesabında izlenecektir. Personelin işverene maliyeti aşağıdaki Tablo 7'de gösterilmektedir.

Tablo 7. Personelin İşverene Toplam Maliyeti

\begin{tabular}{|l|l|r|}
\hline SGK İşveren Pay1 & $6.000 \mathrm{TL} \times 20,5$ & $1.230 \mathrm{TL}$ \\
\hline SGK İşsizlik Sigortası İşveren Pay1 & $6.000 \mathrm{TL} \times \mathrm{\%} \% 2$ & $120 \mathrm{TL}$ \\
\hline İşverene Maliyet: $6.000 \mathrm{TL}+1.230 \mathrm{TL}+120 \mathrm{TL}=7.350 \mathrm{TL}$ & \\
\hline
\end{tabular}

Yukarıda yapılan hesaplamaların ardından hesaplanan tutarların muhasebe kaydı aşağıdaki gibi olacaktır. Personelin işverene toplam maliyeti 740 Hizmet Üretim Maliyeti hesabının borcuna, personelin asgari geçim indirimi 136 Diğer Çeşitli Alacaklar hesabının borcuna yazılacaktır.

740 HIZZMET ÜRETIM MALIYETİ

136.DİĞERÇEŞİTLİ ALACAKLAR

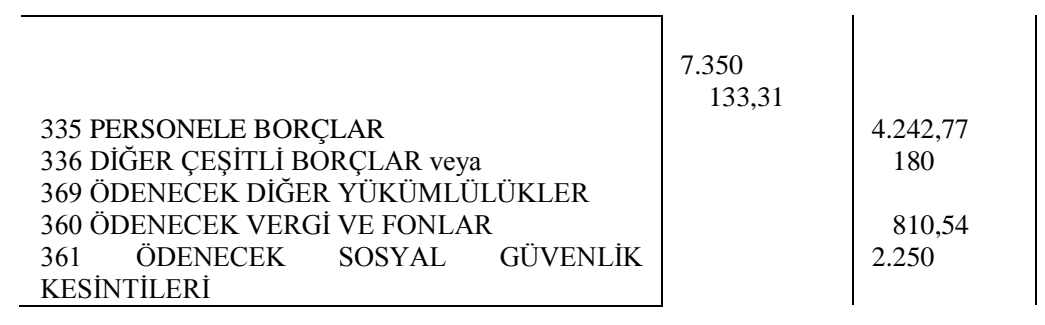


Personele ödenecek net tutar "335 Personele Borçlar” hesabına tahakkuk ettirilecektir. Gelir ve Damga Vergisi "360 Ödenecek Vergi ve Fonlar”, İşçi ve işverenden kesilen SGK kesintileri "361 Ödenecek Sosyal Güvenlik Kesintileri" hesabına kaydedilecektir. Personelin ücretinden yapılan Bireysel Emeklilik kesintisi tutarı "336 Diğer Çeşitli Borçlar” veya "369 Ödenecek Diğer Yükümlülükler” olarak muhasebeleştirilecektir.

\section{Örnek 2}

Asgari ücretle çalışan bir hastane personelinin Ocak ayı ücretinden yapılacak kesinti oranları ve tutarları aşağıdaki gibidir. Personel evlidir, eşi çalışmamaktadır ve personel 3 çocuk sahibidir.2017 yılı brüt asgari ücret tutarı 1.777,50 TL'dir. Bu bilgilere göre:

SGK İşçi Payı: \%14

SGK İşsizlik Sigortası İşçi Payı: \%1

B.E.S. :\%3

Gelir Vergisi: \%15
SGK İșveren Payı: \%20,5

SGK İşsizlik Sigortası İşveren Payı: \%2

Damga Vergisi:\%0,759

A.G.I. : $226,63 \mathrm{TL}$

Asgari ücret ile çalışan personel ile ilgili yapılacak kesintiler Tablo 8'de gösterilmiştir. Evli, eşi çalışmayan 3 çocuklu bir personelin ödeyeceği gelir vergisi ile asgari geçim indirimi aynı tutardadır.

Tablo 8. Asgari Ücretli Çalışanın Ücretinden Yapılacak Kesinti Tutarları

\begin{tabular}{|c|c|c|}
\hline SGK İşçi Pay1 & $1.777,50$ TL $\mathrm{x} \% 14$ & $248,85 \mathrm{TL}$ \\
\hline SGK İşsizlik Sigortası İşçi Payı & 1.777,50 TL x \%1 & $17,77 \mathrm{TL}$ \\
\hline Gelir Vergisi & $\begin{array}{l}{[1.777,50 \mathrm{TL}-(248,85 \mathrm{TL}+17,77} \\
\mathrm{TL})] \mathrm{x} \% 15\end{array}$ & $226,63 \mathrm{TL}$ \\
\hline Damga Vergisi & $1.777,50$ TL $x \% 0,759$ & $13,49 \mathrm{TL}$ \\
\hline B.E.S. & $1.777,50$ TL $x \% 3$ & $53 \mathrm{TL}$ \\
\hline
\end{tabular}

Asgari ücretli personelin vergi ve sigorta kesintilerine ek olarak yeni düzenleme ile birlikte ücretinden 53 TL BES kesintisi yapılacaktır. Asgari ücretli personelin işverene maliyeti ise Tablo 9'da gösterilmiştir.

Tablo 9. Asgari Ücretli Çalışan Personelin İşverene Toplam Maliyeti

\begin{tabular}{|l|l|c|}
\hline SGK İșveren Pay1 & $1.777,50 \mathrm{TL} \times \% 20,5$ & $364,38 \mathrm{TL}$ \\
\hline SGK İșsizlik Sigortası İşveren Pay1 & $1.777,50 \mathrm{TL} \times$ \%2 & $35,55 \mathrm{TL}$ \\
\hline İşverene Maliyet: $1.777,50 \mathrm{TL}+364,38 \mathrm{TL}+35,55 \mathrm{TL}=2.177,43 \mathrm{TL}$ & \\
\hline
\end{tabular}

2017 yllı itibariyle asgari ücretli çalışan bir personelin işverene maliyeti 2.177,43 TL'dir. Yapılan hesaplamalar ile ilgili yapılması gereken kayıt aşağıda gösterilmiştir. 
740 HIZMET ÜRETIM MALIYETLERI 136 DİĞER ÇEŞITLII ALACAKLAR

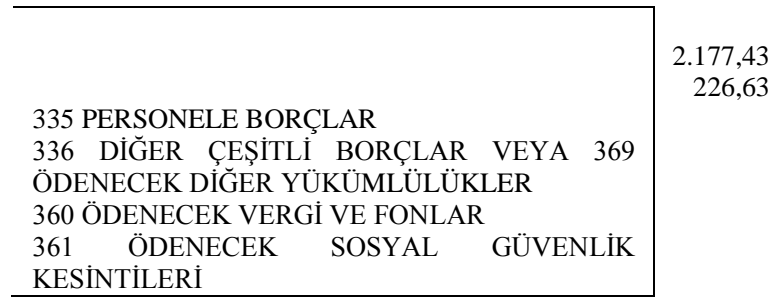

\section{SONUÇ VE ÖNERİ}

2017 yılı itibariyle Bireysel Emeklilik Sistemi kamu kurumlarında ve özel sektörde 45 yaş altı tüm çalışanlara zorunlu kılınmıştır. Çalışan personelin brüt ücreti üzerinde $\% 3$ tutarında kesinti işveren tarafindan yapılacaktır. Yapılan bu kesintiler daha sonra işveren tarafından ilgili sigorta şirketine ödenecektir. Bu çalışmada bireysel emeklilik sistemine zorunlu katılım sonrası yapılacak hesaplamalar ve kullanılacak hesap önerilerine yer verilmiştir. Yapılan kesinti tutarı devlet kurumlarına ödenmediği için "361 Ödenecek Sosyal Güvenlik Kesintileri” hesabının kullanımı doğru olmayacaktır. Bu yüzden yapılacak kesinti için yeni bir hesap tanımlanması mümkündür. Bunun dışında mevcut hesaplardan "336 Diğer Çeşitli Borçlar" veya "369 Ödenecek Diğer Yükümlülükler" hesaplarından birinin kullanılmasının doğru olacağı düşünülmektedir.

\section{KAYNAKLAR}

Apak Sudi- Taşçıyan Kamer Hagop (2010) “Türkiye’de Bireysel Emeklilik Sisteminin Gelişimi” Ekonomi Bilimleri Dergisi, Cilt 2, Sayı 2, ss: 121-129.

Arsoy, Aylin Poroy (2014) Finansal Muhasebe 1. Bask1. Bursa : Dora Yayıncılık.

Bireysel Emeklilik Tasarruf ve Yatırım Sistemi Kanunu (2001). 4632 Sayılı Kanun. Resmi Gazete: 24366.

Çalışanların İşverenleri Aracılığıyla Otomatik Olarak Emeklilik Planına Dâhil Edilmesine İlişkin Usul ve Esaslar Hakkında Yönetmelik (2017). Hazine Müsteşarlığı.

Emeklilik Gözetim Merkezi. http://www.egm.org.tr (19.01.2017)

Gelir İdaresi Başkanlığı, 265 Seri No'lu Gelir Vergisi Genel Tebliği. Resmi Gazete: 26720, Resmi Gazete Tarihi: 04.12.2007

İşseveroğlu Gülsün- Hatunoğlu Zeynep (2012) “Türkiye’de Bireysel Emeklilik Sisteminin Makro Ekonomik Dinamiklere Etkisi Kapsamında Swot Analizi” Muhasebe ve Finansman Dergisi, Say1: 56, ss: 155-174.

Kızılgeçit Zeynep (2014) "Bireysel Emeklilik Sistemi Ve Bireysel Emeklilik Sistemindeki Sigorta Şirketlerinde Fon Yönetimi” Atatürk Üniversitesi Sosyal Bilimler Enstitüsü Basılmamış Yüksek Lisans Tezi.

Sezgin Selami ve Yıldırım Tuba (2015) “Türkiye' de Bireysel Emeklilik Sisteminin Etkinliği” Eskişehir Osmangazi Üniversitesi İ̈BF Dergisi, Ağustos 2015, 10(2), ss.123- 140 
Sosyal Güvenlik Kurumu. www.sgk.gov.tr. ( 20.01.2017)

Uyar Hilal İlgin (2012) "Bireysel Emeklilik Sistemi ile Ekonomik Göstergeler Arasındaki İlişkinin İncelenmesi”, Mali Çözüm Dergisi, Sayı: 110, ss: 71-93.

Yaman Okan- Emir Murat (2012) "Bireysel Emeklilik Sisteminin Denetim ve Muhasebe Yapısı”, Mali Çözüm Dergisi, Sayı:110, ss: 55-70. 